\title{
Development of the Groundwater Level Changes Detector for Earthquake Prediction at Yogyakarta Region - Indonesia
}

\author{
Herlambang Laksamana Firdaus ${ }^{1 *}$, Sunarno ${ }^{2}$, Memory Motivanisman Waruwu ${ }^{2}$, and Rony \\ Wijaya $^{3}$ \\ ${ }^{1}$ Student of Magister Engineering Physics, Department of Nuclear Engineering and Engineering \\ Physics, Universitas Gadjah Mada, Jl. Grafika 2, Sleman, D.I.Yogyakarta, Indonesia \\ ${ }^{2}$ Sensor and Tele-control Laboratory, Department of Nuclear Engineering and Engineering Physics, \\ Universitas Gadjah Mada, Jl. Grafika 2, Sleman, D.I.Yogyakarta, Indonesia \\ ${ }^{3}$ Production House Unit, Faculty of Medicine, Universitas Gadjah Mada, Jl. Farmako no 2 Sekip \\ Utara, Sleman, D.I.Yogyakarta, Indonesia
}

\begin{abstract}
Groundwater level (GWL) change is one of the earthquake precursors that used for earthquake prediction. The groundwater level change system detector for earthquake prediction at Yogyakarta region Indonesia contains the GWL detector, signal conditioner, controller, data storage and electrical power supply. The GWL changes detectors which are developed in this report are expected to be used for the earthquake precursors prediction in Yogyakarta region - Indonesia. The detector system shows the detection of groundwater level changes with a sensitivity of 0.01 centimeters. The data from the detector is stored on the storage media, then the data which are collected in weekly will be confirmed with the earthquake data from the BMKG (Indonesian Meteorology, Climatology, and Geophysics Agency). On June 11, 12, 15, and 21 the GWL have a change of 4 centimeters to 19 centimeters respectively, the earthquake occurs within the next 2 days. It shows that the system could be used as an earthquake precursors monitoring system based on GWL changes. This report in order to give the valuable information of the development system that can be used for earthquake prediction, even though it needs further study and development of the instrumentation system from other earthquake precursors anomaly.
\end{abstract}

\section{Introduction}

A reliable earthquake precursor can save thousands of lives each year all over the world. Several instrumentation systems have been developed related to earthquake precursor anomaly. Many engineers and scientist are trying to establish this fact as a reliable precursor of the earthquake. Study of earthquake precursors may hold promise in advancing the science of short-term earthquake prediction. As a short-term earthquake

* Corresponding author: edhalaksamana@gmail.com 
prediction, earthquake precursors are usually based on observations of various physical phenomena that are reported at least some earthquakes before. The precursor phenomena include groundwater level changes, induced electric and magnetic fields, surface deformations, gas emissions, temperature changes, radon concentration anomalies, and many more [1].

Earthquake prediction is poorly understood, how the future earthquakes occurred can be determined from the behavior before the earthquake occurred. The poor understanding is reflected in the inability to predict major earthquakes in seismically active regions within a short period of time. The observable signal before earthquakes that indicates with high probability the location, time, and magnitude of an impending event is the most proposed prediction methods rely on the concept of a diagnostic precursor. The research for diagnostic precursors has not yet got a successful short-term prediction scheme [2].

The previous research has found that the earthquake occurred when the detector gets a groundwater level change at 4 to 50 days before the earthquake [3]. This paper discusses the earthquake prediction state of the art and the main issues which are deduced from fluctuations in groundwater levels in the Yogyakarta-Indonesia region, and it concluded by discussing the challenges of the future of the domain.

\section{Literature}

\subsection{Deterministic Earthquake Prediction deduced from Changes in Groundwater Level}

216 wells were observed in China mainland to figure out the relationship of groundwater level changes induced $2011 \mathrm{Mw}=9.0$ Tohoku earthquake as an earthquake prediction at epicenter distances between 1300 and $5400 \mathrm{~km}$. Out of 216 wells operating during the time of the event, 85 wells showed the groundwater level oscillations during the passage of the seismic waves. The sustained changes that are evenly distributed between those experiencing groundwater level rise and falls were showed on 73 wells. At the remaining 58 wells, no response to the earthquake was observed. Observed response in terms of distance or in terms of azimuth with respect to the epicenter showed was no spatial pattern in the different well response types is evident. Statistical analysis showed that wells that responded to the Tohoku earthquake were characterized by the changes above $0.5 \mathrm{~m}$ in water level per microstrain in accordance with $5 \mathrm{kPa}$ changes in water pressure per microstrain or $5 \mathrm{GPa}$, while most wells those who respond are characterized by lower tidal factors. The sensitivity of the well-aquifer response is about 80 percent. However, coseismic oscillations/fluctuations showed has no systematic difference in tidal admittance factors or phases can be seen between wells that displayed sustained changes. To shows the changes in the aquifer permeability, post-seismic phase shifts were observed at 31 sites, positive in 22 cases and negative in nine cases. Accordingly, 43 percent of those wells that displayed sustained water level changes as earthquake-induced temporal variations in the permeability might have occurred, but less than 15 percent of all observed wells. Statistical methods also used to analyze the relationships between the different types of groundwater level changes and the earthquake system [4].

\subsection{Identification the groundwater level as an earthquake signals}

The coseismic signals of groundwater levels are generally caused by Earth tides, the diminished of atmospheric pressure response and precipitation from the observed data. However, the coseismic signal is often difficult to be extracted if observations are made far from a barometer, pluviometers or tidal data for correction. In this case, To obtain the instantaneous frequency and amplitude for each point of the decomposed intrinsic mode 
function (IMF) of groundwater level data to distinguish the response that depends on the associated frequency without further additional input, the Hilbert-Huang transform (HTT) is usually used. The extracted coseismic signal shows a strong amplitude pulse seen clearly in the third IMF. Furthermore, two types of coseismic signals can be easily distinguished in the results of the HHT transformation. One of them is the instantaneous short time signal caused by the passage of seismic waves. Another peak of the earthquake and the magnitude of the earthquake at Hualien Station, Taiwan and showed a positive correlation between the distance of the earthquake and its magnitude [5].

\section{Methodology}

\subsection{The System Detectors}

The system detectors were placed at remote area consisting of the GWL transducers, and signal conditioning. The system detector contains the GWL detector, signal conditioning, controller, data storage and electrical power supply. It has specification such as Photovoltaic 50WP, PV controller MPPT 5A $12 \mathrm{~V}$, accumulator battery power $12 \mathrm{~V}$, data storage $16 \mathrm{~GB}$, and system sensitivity 0.01 centimeter. The block diagram of the monitoring station is shown in Fig. 1.

Block Diagram of the Detector System

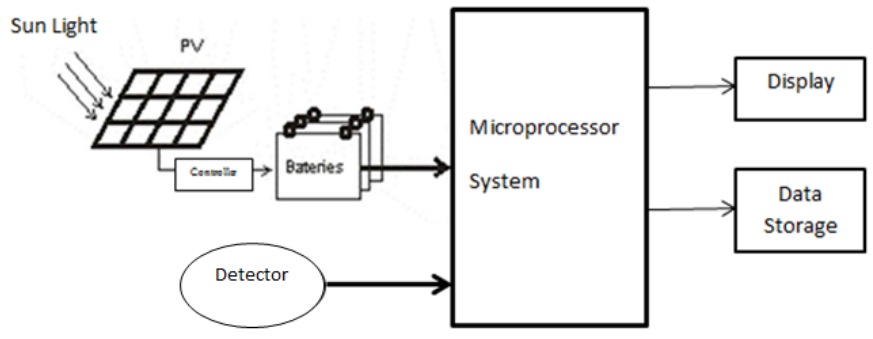

Fig. 1 Block Diagram of The Monitoring Station System

\subsection{Tests and Evaluations}

The stages of development are:

1. Create and compiled the instrumentation system on the basis of the developed model.

2. Create the program for the purposes of control and collection of data as well as developing a data management system.

3. Test in simulation stages to obtain the level of accuracy and speed of data access from data sources.

4. Revise the model developed on the basis of the data obtained and re-testing the system to obtain the results as expected.

5. Test in laboratory scale to make sure the result of the system is calibrated according to standard.

6. Placed the system into the remote area (chosen water wells) to validate the system are related to the anomaly before the earthquake occurred.

\section{Result and Discussion}

\subsection{Data System Test}


In this section, the detector output shown in the system display is the centimeter unit and will be compared to the standard gauge. The detector will be drowned every centimeter and then the output yield that shown on the system display will be recorded. The test was performed as many as 25 variations of the depth and replicated as much as 5 times test. After the data obtained, the next step is to do the analysis using the statistical method i.e comparison method. Fig. 2 presents the results of the comparison method analysis with an accuracy of $85 \%$ which is displayed in the box plot.

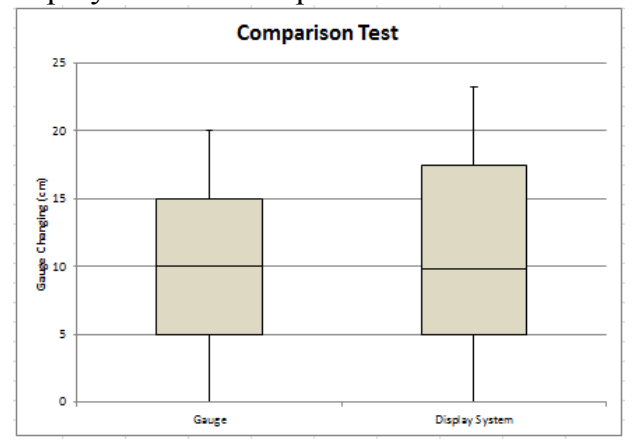

Fig. 2 Box Plot from Comparison Method between the Detector and Standard Gauge

Fig. 2 shows that the output of the system is not much different from the standard gauge.

\subsection{System Validation}

The groundwater level changes detector placed on the chosen water wells with the requirement the wells is rarely to use on a human activity. The system supported with a power system that contains photovoltaic, controller, and accumulator battery. Data that been recorded in the data storage, will be validated to the earthquake data from BMKG (Indonesian Meteorology, Climatology, and Geophysics Agency). It will be shown the relationship between groundwater level changes and the occurred earthquake.

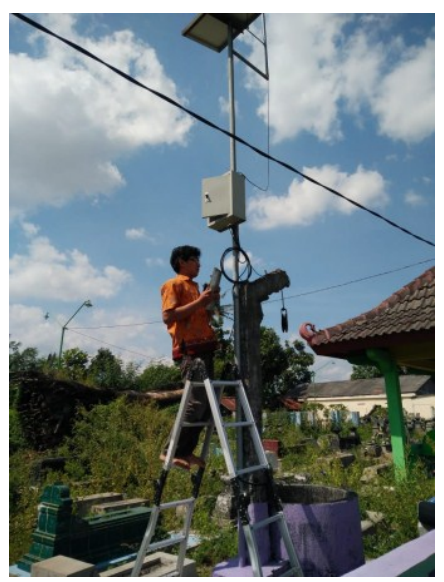

Fig. 3 Implementation of Groundwater Level Detector

The data has been recorded by the detector system stored on the SD card. The data is analyzed on a weekly interval test, and the reliability of the system against earthquake will be recorded outside the system. The data shows that the detector system can detect groundwater level changes with a sensitivity of 0.01 centimeters. 
The Results of Groundwater Level Monitoring for 14 days, as follow:

- Location: Detector 1 at $07^{\circ} 81^{\prime} 90.13 " \mathrm{~S}, 110^{\circ} 52^{\prime} 07.14^{\prime \prime} \mathrm{E}$ (Wukirharjo water well) and Detector 2 at $07^{\circ} 76^{\prime} 20.43^{\prime \prime S}, 110^{\circ} 53^{\prime} 12.82^{\prime \prime}$ E (Muruh water well)

- Range: June 8, - June 21, 2018

- The earthquake was occurred in Mentawai Indonesia (June 13, 2018), Mentawai Indonesia (June 14, 2018), Bantul Indonesia (June 17, 2018), and Indramayu Indonesia (June 23, 2018).

- The groundwater level changes that detected by the system several days before the earthquake is \pm 4 centimeters per day for Wukirharjo water well and \pm 19 centimeters per day for Muruh water well.

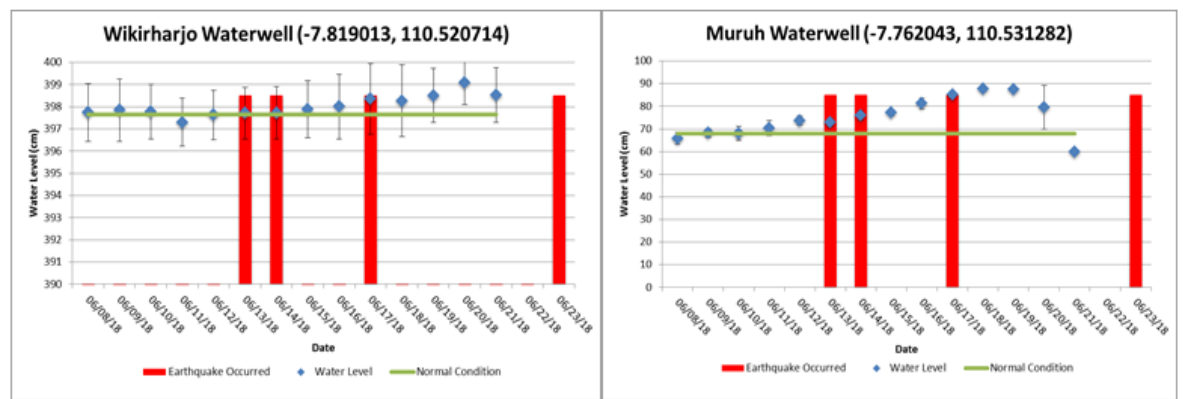

Fig. 4 Graph of The Relationship of Groundwater Level Changes and Earthquake Occurred

Fig. 5 shows the example of an earthquake that occurred in the research range time, i.e an earthquake event that occurred in Bantul Indonesia.

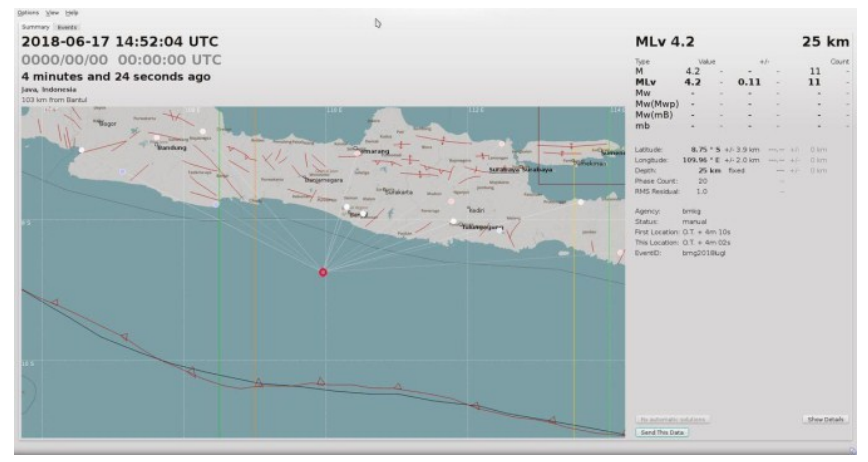

Fig. 5 Picture of Bantul Indonesia Earthquake on June 17, 2018 [6]

\section{Conclusion}

This research informs the detector system which is used for detecting the fluctuation of groundwater level as an earthquake prediction that placed on Yogyakarta Region Indonesia. The system which developed in this report is expected to be used in detector system for earthquake prediction deduced from fluctuations at Yogyakarta Region Indonesia.

The results of the detection system test at Yogyakarta region indicate that the groundwater level changes that recorded on the system have a relationship with the occurred earthquake. On June 11, 12, 15, and 21 the GWL have a change of 4 centimeters to 19 centimeters respectively, the earthquake occurs within the next 2 days. 
It shows that the system can be used as an earthquake monitoring system based on the groundwater levels changes. It can be used for earthquake prediction even though needs further study and development of the database system. This report is expected to give valuable information from developing the system that can be used for earthquake prediction.

Acknowledgment

I would like to thank the Sensor and Tele-control Laboratory UGM and Production House UGM who supported my work in this way and helped me get the result of better quality.

\section{References:}

1. R. D. Cicerone, J. E. Ebel, and J. Britton, "A systematic compilation of earthquake precursors," Tectonophysics, vol. 476, no. 3-4, pp. 371-396, Oct. 2009.

2. T. Jordan et al., "Operational Earthquake Forecasting. State of Knowledge and Guidelines for Utilization," Ann. Geophys., vol. 54, no. 4, Aug. 2011.

3. Sunarno, M. M. Waruwu, and R. Wijaya, "Development of the real-time telemonitoring system for earthquake prediction deduced from fluctuations in groundwater levels at Yogyakarta region-Indonesia," J. Theor. Appl. Inf. Technol., vol. 83, no. 1, pp. 95-99, 2016.

4. R. Yan, H. Woith, and R. Wang, "Groundwater level changes induced by the 2011 Tohoku earthquake in China mainland," Geophys. J. Int., vol. 199, no. 1, pp. 533-548, 2014.

5. C.-H. Chen et al., "Identification of earthquake signals from groundwater level records using the HHT method," Geophys. J. Int., vol. 180, no. 3, pp. 1231-1241, Mar. 2010.

6. BMKG, "Gempabumi-Terkini." [Online]. Available: http://www.bmkg.go.id/gempabumi/gempabumi-terkini.bmkg. [Accessed: 11-Jul2018]. 